\title{
Examining Parental Treatment Decisions Within a Contemporary Pediatric Dentistry Private Practice
}

\section{Kayla Kopczynski' \\ Beau D Meyer ${ }^{2}$}

'Adams School of Dentistry, University of North Carolina-Chapel Hill, Chapel Hill, NC, USA; ${ }^{2}$ Division of Pediatric Dentistry, College of Dentistry, Ohio State University, Columbus, OH, USA
Correspondence: Beau D Meyer

The Ohio State University, College of Dentistry, Division of Pediatric Dentistry, Columbus, OH, USA

Email meyer.781@osu.edu
This article was published in the following Dove Press journal: Patient Preference and Adherence

Purpose: The primary objective of this study was to compare relationships between child, parent, and clinical factors with patient-level treatment decisions for early childhood caries. A secondary objective was to describe children that received silver diamine fluoride (SDF) as interim versus long-term treatment.

Patients and Methods: Parents of 2-6-year-old children seeking care at a multi-center pediatric dentistry private practice were enrolled in this cross-sectional study. Demographic data and dental anxiety data according to the Modified Corah's Dental Anxiety Scale were collected via questionnaire. A dental visit behavior rating and decayed, missing, and filled tooth $(\mathrm{dmft})$ index were recorded from the child's dental record. The primary outcome was treatment decision categorized into three groups: (1) treatment with SDF ( $n=25)$, (2) conventional restorative treatment under local anesthesia $(n=32)$, and (3) restorative treatment under general anesthesia $(n=33)$. Analyses included descriptive statistics, bivariate analysis, and ordered logistic regression.

Results: Child age, parent education level, family income, dental insurance status, dental visit behavior rating, and $\mathrm{dmft}$ were significantly different across treatment groups in bivariate comparisons. However, when included in multivariable, ordered logistic regression, child dental anxiety was the only significant covariate associated with treatment decisions (Odds Ratio $=5.01$, 95\% confidence interval: 1.51 to 16.63 ). In secondary analysis, two distinct subgroups were identified within the SDF group: one as long-term treatment $(n=9)$ and one as interim treatment prior to general anesthesia $(n=16)$. The long-term group was younger (mean=3.2 versus 3.7), had lower $\mathrm{dmft}$ (mean=4 versus 11.1), and had lower frequency of very high dental anxiety ( $0 \%$ versus $15 \%)$.

Conclusion: The present study identified child dental anxiety as the primary factor associated with treatment decisions at this private practice. The characterization of two subgroups of children treated with SDF has meaningful implications for studies evaluating the economic and public health impacts of SDF.

Keywords: dental caries, early childhood caries, preventive dentistry

\section{Introduction}

Dental caries remains a highly prevalent disease among young children. Once initiated, the caries process can progress rapidly, especially in the primary dentition. Among children worldwide, early childhood caries (ECC) is five times more common than asthma, and twenty times more common than juvenile diabetes. ${ }^{1}$ ECC negatively impacts the quality of life for affected children and their families. ${ }^{2,3}$ Aside from pain and discomfort, consequences of untreated decay in the primary dentition include: 
high treatment costs, ${ }^{4}$ increased visits to hospital emergency rooms, ${ }^{5}$ missed days from school and work to accommodate dental treatment, ${ }^{6}$ and increased risk of caries in the future permanent dentition. $^{7}$

Individualized, patient-level treatment decisions for managing ECC must consider the relative inputs of a child's disease extent and severity, behavior, as well as family, social, and societal factors. ${ }^{8}$ Additionally, dental fear or anxiety in young children may result in poor dental visit behaviors. ${ }^{9}$ Conventional treatment of ECC frequently involves a surgical treatment under local anesthesia in the dental office. For fearful or anxious children, or for those who lack the ability to cooperate for safe conventional treatment, clinicians and parents must consider the risks, benefits, and costs of alternative treatment options. ${ }^{10-13}$ Increasingly, these alternatives include nonsurgical or minimally invasive treatment, the use of sedation or general anesthesia (GA) to facilitate dental treatment, or some combination of these two extremes. ${ }^{14,15}$

Clinically effective, nonsurgical treatments present opportunities to limit morbidity associated with ECC. ${ }^{16}$ Silver diamine fluoride (SDF) is one nonsurgical treatment option that may play a large role in chronic management of ECC. Applied topically, SDF presents a safe, affordable, and atraumatic treatment option for many young patients. While SDF is highly effective against caries in the primary dentition, it also permanently stains affected tooth structure and does not restore missing tooth structure, which has limited its widespread clinical acceptance and application. ${ }^{17}$ SDF is often utilized to halt the progression of disease until the child is able to cooperate for conventional treatment or in situations where delays in scheduling conventional treatment are unavoidable (i.e., long waitlists for treatment). ${ }^{18}$

The primary objective of this study was to compare relationships between child, parent, and clinical factors with patient-level treatment decisions for ECC. A secondary objective was to describe children who received SDF to manage ECC and to elucidate instances when it was used as long-term versus interim treatment. Based on American Academy of Pediatric Dentistry guidelines, the hypothesis was that child behavior had the strongest relationship with treatment decisions.

\section{Methods}

This study was reviewed and approved by the Institutional Review Board at the University of North Carolina at Chapel Hill Adams School of Dentistry (18-0785). This clinical cross-sectional study used both patient records and parent-reported surveys from a multicenter pediatric dentistry private practice in Charlotte, North Carolina.

\section{Practice Profile}

The private practice spans five locations across two counties, one urban and one rural, and employs six pediatric dentists and one general dentist, whose practice is limited to children. The patient population includes a diverse mix of insurance coverage, race, and family income.

\section{Inclusion Criteria and Sample Size}

Included were children ages 2-6 years, along with their parents, on their first visit to the practice. This criterion was selected to capture a population of children with minimal to no previous experience with dental treatment. Children who required extractions or pulp therapy were excluded, since these teeth are contraindicated to receive SDF. A consecutive convenience sample of 138 English and Spanish speaking parent-child pairs were recruited and voluntarily enrolled between September 2018 and October 2019. Parental informed consent was obtained for each patient at the time of enrollment to comply with the Declaration of Helsinki.

\section{Data Collection}

Parents completed three validated questionnaires. The first was a household demographic survey including child, parent, and family information, such as child and parent's age, gender, race, ethnicity, dental insurance status; the parent's highest education level; family income; and county of residence. The second was a 5-item Modified Corah's Dental Anxiety Scale (MDAS) ${ }^{19}$ completed twice, once for themselves and once on behalf of their child.

The child received a dental exam, prophylaxis, fluoride, and radiographs as indicated. If caries lesions were identified, the dentist and parent developed a treatment plan for the child using shared decision-making. While no randomization occurred, the shared decision-making allowed parents to reach a decision they felt was best for their child.

Three variables were derived from the child's dental record: the child's level of cooperation during the appointment, measured by the Frankl Behavior Assessment; ${ }^{20}$ a decayed, missing, filled primary tooth (dmft) index; and the treatment plan selected by the parent. Frankl behavior scores are assigned by clinical staff at every visit to the practice. The treatment notes 
contain the score, and depending on the situation, additional description is added for clarity. Clinical staff are calibrated on the Frankl Behavior Assessment at onboarding, and select patients are reviewed at monthly staff meetings for consistency in documentation. The $\mathrm{dmft}$ index for each child was calculated from the patient's record by a single study team member using the subject's dental charting. Some parents required additional time to consider options and make a final treatment decision for their child. To accommodate these situations, and to ensure accurate data collection, records of enrolled children were reviewed retroactively to determine if any treatment decisions changed.

Study groups were identified as follows:

1. Treatment with SDF,

2. Conventional in-office restorative treatment under local anesthesia, and

3. Restorative treatment using hospital-based GA.

Children with no treatment needs were included as a control group for demographic comparison between groups.

In this practice, the dentists' decision to recommend SDF treatment to a parent relied heavily on the child's ability to cooperate. When an uncooperative or precooperative child presented with extensive needs, SDF was offered to parents as an interim treatment option to delay the progression of disease until either (1) the child reached a cooperative level for conventional in-office restorative treatment under local anesthesia or (2) the parent subsequently opted for treatment under GA. When an uncooperative or pre-cooperative child presented with only minor restorative needs, SDF was offered to parents as both a long-term and interim treatment option for managing the child's ECC. The treating dentist and the child's parent collectively agreed on a treatment decision for children in this study.

\section{Statistical Analysis}

In addition to the variables collected in the demographic survey, dental anxiety was included as an independent variable in two steps. First, each item of the MDAS is scored from 1 (not anxious) to 5 (extremely anxious), with total score range of 5-25. Then, total scores were coded dichotomously for absence (MDAS <19) or presence (MDAS $\geq 19$ ) of very high dental anxiety. ${ }^{21}$
Study groups were compared using descriptive and bivariate analysis. Based on the data distribution, nonparametric Kruskal-Wallis tests were used for demographic comparisons. Spearman rank correlation coefficients were calculated to identify general relationships between variables.

Ordered logistic regression was used to explore relationships of child, parent, and clinical variables with the selected treatment decision. The outcome was treatment decision ordered by invasiveness: SDF, conventional inoffice restorative treatment under local anesthesia, and restorative treatment using hospital-based GA. For this analysis, the control group was omitted since the treatment decision was impossible for them - they did not have caries. A 3-level ordinal outcome requires a minimum sample size of $80 .{ }^{22}$ A $15: 1$ ratio between the minimum sample size and number of covariates in the model allows for inclusion of up to five covariates. In the present model, five covariates (child age, dmft, child very high dental anxiety, and dental insurance status [counted as two]) were included, thereby rendering the sample size of the study sufficient to ensure reliability of the model. ${ }^{22}$ The included covariates aligned with existing algorithms and frameworks for dental caries and treatment decisions. ${ }^{14,23}$

Secondary analysis included comparisons between groups where treatment decisions changed. The SDF group received additional consideration based on its longterm or interim use.

For all analyses, which were completed using Stata 15.1, statistical significance was set at alpha equals 0.05 (STATACORP, LLC., College Station, TX, USA).

\section{Results}

This study included 138 children aged 2-6 years old and their parents (Table 1). The mean child age was 3.4 years $(\mathrm{sd}=1.6)$. Approximately two-thirds of parents reported having an education beyond high school, and nearly onehalf reported a family income of less than $\$ 45,000$ per year. Approximately two-thirds (63\%) of children were Medicaid recipients. Parent income was significantly correlated with education level $(\mathrm{r}=0.47)$ and insurance status $(\mathrm{r}=0.54)$.

Among the children in study groups, $28 \%$ of parents selected treatment with SDF $(n=25), 35 \%$ selected conventional restorative treatment under local anesthesia $(n=32)$, and $37 \%$ selected restorative treatment under GA $(n=33)$. Enrolled children with no treatment needs were designated as a control group $(n=48)$. Children in the 
Table I Demographic Characteristics and Data Summary of Sample

\begin{tabular}{|c|c|c|c|c|c|}
\hline & Control & $\begin{array}{l}\text { Treatment with } \\
\text { Silver Diamine } \\
\text { Fluoride (SDF) }\end{array}$ & $\begin{array}{l}\text { Conventional In- } \\
\text { Office Restorative } \\
\text { Treatment }\end{array}$ & $\begin{array}{l}\text { Restorative Treatment } \\
\text { Using Hospital-Based } \\
\text { General Anesthesia }\end{array}$ & p-value ${ }^{a}$ \\
\hline Total Participants (N) & 48 & 25 & 32 & 33 & \\
\hline Child Age, in Years (Mean, SD) & $3.5(1.3)$ & $3.5(1.1)$ & $4.9(0.8)$ & $3.6(1.1)$ & $<0.001$ \\
\hline $\begin{array}{l}\text { Gender }\left(\mathbf{n}, \%^{\mathbf{b}}\right) \\
\text { Female } \\
\text { Male } \\
\text { Missing }\end{array}$ & $\begin{array}{c}29(60 \%) \\
17(35 \%) \\
3(4 \%)\end{array}$ & $\begin{array}{l}12(48 \%) \\
\text { II (44\%) } \\
2(2 \%)\end{array}$ & $\begin{array}{l}20(63 \%) \\
\text { II }(34 \%) \\
\text { I }(3 \%)\end{array}$ & $\begin{array}{c}16(48 \%) \\
15(45 \%) \\
2(6 \%)\end{array}$ & 0.6 \\
\hline $\begin{array}{l}\text { Race/Ethnicity of Child Patient } \\
\text { (n, \% }{ }^{\mathbf{b}} \text { ) } \\
\text { Caucasian } \\
\text { African American or Black } \\
\text { Hispanic } \\
\text { Asian } \\
\text { Other } \\
\text { Missing }\end{array}$ & $\begin{array}{c}18(38 \%) \\
\text { I8 (38\%) } \\
4(8 \%) \\
5(10 \%) \\
2(4 \%) \\
\text { I (2\%) }\end{array}$ & $\begin{array}{c}4(16 \%) \\
13(52 \%) \\
5(20 \%) \\
3(12 \%) \\
0(0 \%) \\
0(0 \%)\end{array}$ & $\begin{array}{c}13(41 \%) \\
12(38 \%) \\
2(6 \%) \\
2(6 \%) \\
3(9 \%) \\
0(0 \%)\end{array}$ & $\begin{array}{c}6(18 \%) \\
15(42 \%) \\
4(12 \%) \\
5(15 \%) \\
1(3 \%) \\
2(6 \%)\end{array}$ & 0.2 \\
\hline $\begin{array}{l}\left.\text { County of Residence (n, \% }{ }^{\mathbf{b}}\right) \\
\text { Rural } \\
\text { Urban } \\
\text { Missing }\end{array}$ & $\begin{array}{c}5(10 \%) \\
43(90 \%) \\
0(0 \%)\end{array}$ & $\begin{array}{c}8(32 \%) \\
17(68 \%) \\
0(0 \%)\end{array}$ & $\begin{array}{c}7(22 \%) \\
25(78 \%) \\
0(0 \%)\end{array}$ & $\begin{array}{c}10(30 \%) \\
21(64 \%) \\
2(6 \%)\end{array}$ & 0.07 \\
\hline $\begin{array}{l}\text { Parent Education Level }\left(\mathbf{n}, \%^{\mathbf{b}}\right) \\
\text { High school or less } \\
\text { Some college or Bachelor's } \\
\text { Master's or above } \\
\text { Missing }\end{array}$ & $\begin{array}{l}9(19 \%) \\
26(54 \%) \\
11(23 \%) \\
2(4 \%)\end{array}$ & $\begin{array}{l}8(32 \%) \\
\text { I5 (60\%) } \\
\text { I (4\%) } \\
\text { I (4\%) }\end{array}$ & $\begin{array}{l}10(31 \%) \\
16(50 \%) \\
5(16 \%) \\
1(3 \%)\end{array}$ & $\begin{array}{l}14(42 \%) \\
14(42 \%) \\
2(6 \%) \\
3(9 \%)\end{array}$ & 0.03 \\
\hline $\begin{array}{l}\text { Family Income }\left(\mathbf{n}, \%^{\mathbf{b}}\right) \\
<\$ 45,000 \\
\$ 45,001-75,000 \\
>\$ 75,001 \\
\text { Missing }\end{array}$ & $\begin{array}{c}14(29 \%) \\
4(8 \%) \\
19(40 \%) \\
11(23 \%)\end{array}$ & $\begin{array}{l}\text { II (44\%) } \\
6(24 \%) \\
0(0 \%) \\
8(32 \%)\end{array}$ & $\begin{array}{l}13(41 \%) \\
7(22 \%) \\
8(25 \%) \\
4(13 \%)\end{array}$ & $\begin{array}{l}21(64 \%) \\
7(21 \%) \\
1(3 \%) \\
4(12 \%)\end{array}$ & $<0.001$ \\
\hline $\begin{array}{l}\text { Family Dental Insurance }\left(\mathbf{n}, \%^{\mathbf{b}}\right) \\
\text { Private Insurance } \\
\text { Medicaid } \\
\text { No Insurance }^{c}\end{array}$ & $\begin{array}{c}17(35 \%) \\
24(50 \%) \\
7(14 \%)\end{array}$ & $\begin{array}{c}4(16 \%) \\
16(64 \%) \\
5(20 \%)\end{array}$ & $\begin{array}{l}13(41 \%) \\
15(47 \%) \\
4(13 \%)\end{array}$ & $\begin{array}{c}3(9 \%) \\
22(67 \%) \\
8(24 \%)\end{array}$ & 0.02 \\
\hline
\end{tabular}

Notes: ${ }^{a}$ Non-parametric Kruskal-Wallis tests. ${ }^{b}$ Column percentage. ${ }^{c}$ No insurance selected on the questionnaire or on file in the patient record.

conventional group were significantly older (mean=4.9) than all other groups (control=3.5, $\mathrm{SDF}=3.5, \mathrm{GA}=3.6$ ). Children without caries (control group) were more frequently from urban geography (90\%) and had parents with higher levels of education (Masters or above $=23 \%$ ), and children treated with GA had parents with lower levels of education (high school or less $=42 \%$ ) compared to other groups. Children treated with GA also came from lower income families $(<\$ 45,000=64 \%)$. Control and conventional subjects had higher frequencies of private insurance compared to the other groups $(35 \%$ and $41 \%$, respectively, compared to $\mathrm{SDF}=16 \%$ and $\mathrm{GA}=9 \%$ ). Approximately onethird of control subjects had a previous dental visit, compared to more than two-thirds of all treatment groups (Table 2). Approximately $20 \%$ of children and $20 \%$ of parents had very high dental anxiety according to the MDAS instrument. The $\mathrm{dmft}$ index was significantly greater for the SDF group (mean=8.5) and GA group (mean=9.6) compared to the conventional group $($ mean $=4)$. 
Table 2 Dental-Related Data Summary

\begin{tabular}{|c|c|c|c|c|c|}
\hline & Control & $\begin{array}{l}\text { Treatment with } \\
\text { Silver Diamine } \\
\text { Fluoride (SDF) }\end{array}$ & $\begin{array}{l}\text { Conventional In- } \\
\text { Office Restorative } \\
\text { Treatment }\end{array}$ & $\begin{array}{c}\text { Restorative Treatment } \\
\text { Using Hospital-Based } \\
\text { General Anesthesia }\end{array}$ & p-value ${ }^{a}$ \\
\hline Total Participants (N) & 48 & 25 & 32 & 33 & \\
\hline $\begin{array}{l}\text { History of Dental Visit }\left(\mathbf{n}, \%^{\mathbf{b}}\right) \\
\text { No } \\
\text { Yes }\end{array}$ & $\begin{array}{l}30(63 \%) \\
18(38 \%)\end{array}$ & $\begin{array}{c}9(36 \%) \\
16(64 \%)\end{array}$ & $\begin{array}{l}12(38 \%) \\
20(63 \%)\end{array}$ & $\begin{array}{c}9(27 \%) \\
24(73 \%)\end{array}$ & 0.01 \\
\hline $\begin{array}{l}\text { Very High Dental Anxietyc, } \\
\text { Child }\left(\mathbf{n}, \%^{\mathrm{b}}\right) \\
\text { No } \\
\text { Yes }\end{array}$ & $\begin{array}{l}38(79 \%) \\
10(21 \%)\end{array}$ & $\begin{array}{c}20(80 \%) \\
5(20 \%)\end{array}$ & $\begin{array}{c}27(84 \%) \\
5(16 \%)\end{array}$ & $\begin{array}{l}20(61 \%) \\
13(39 \%)\end{array}$ & 0.1 \\
\hline $\begin{array}{l}\text { Very High Dental Anxietyc, } \\
\text { Parent (n, \% }) \\
\text { No } \\
\text { Yes }\end{array}$ & $\begin{array}{l}43(90 \%) \\
5(10 \%)\end{array}$ & $\begin{array}{c}20(80 \%) \\
5(20 \%)\end{array}$ & $\begin{array}{c}25(78 \%) \\
7(22 \%)\end{array}$ & $\begin{array}{l}23(70 \%) \\
10(30 \%)\end{array}$ & 0.2 \\
\hline $\begin{array}{l}\text { Frankl Behavior Rating }\left(\mathbf{n}, \%^{\mathbf{b}}\right) \\
\text {-/-, or I } \\
\text {-, or } 2 \\
\text { +, or } 3 \\
\text { +/+, or } 4 \\
\text { Missing }\end{array}$ & $\begin{array}{c}7(15 \%) \\
7(15 \%) \\
30(63 \%) \\
4(8 \%) \\
0(0 \%)\end{array}$ & $\begin{array}{l}4(16 \%) \\
5(20 \%) \\
14(56 \%) \\
2(8 \%) \\
0(0 \%)\end{array}$ & $\begin{array}{c}0(0 \%) \\
3(9 \%) \\
24(75 \%) \\
5(16 \%) \\
0(0 \%)\end{array}$ & $\begin{array}{c}5(15 \%) \\
6(18 \%) \\
20(31 \%) \\
0(0 \%) \\
2(6 \%)\end{array}$ & 0.02 \\
\hline $\mathrm{dmft}^{\mathrm{d}}$ (Mean, SD) & $0.1(0.6)$ & $8.5(4.1)$ & $4(3.0)$ & $9.5(4.1)$ & $<0.001$ \\
\hline
\end{tabular}

Notes: a Non-parametric Kruskal-Wallis tests. ${ }^{b}$ Column percentage. ${ }^{c}$ Modified Corah's Dental Anxiety Index $\geq 19 .{ }^{d}$ Decay, missing, filled primary teeth.

In an ordered logistic regression that modeled treatment decisions against age, race, dmft, insurance status, and the presence of high dental anxiety, children's high dental anxiety was the only covariate significantly associated with treatment decisions (Table 3). Holding other variables constant, increasing child dental anxiety increased the odds by five times of going from SDF to conventional, or more importantly, from conventional to GA $(\mathrm{OR}=5.01,95 \%$ confidence interval (CI): 1.51 to 16.63). Age and dmft increased the odds of deciding on more invasive treatment $(\mathrm{OR}=1.1,95 \% \mathrm{CI}$ : 0.7 to 1.6, $\mathrm{OR}=1.1,95 \% \mathrm{CI}: 1.0$ to 1.23 , respectively); however, this was not statistically significant.

In secondary analysis, the SDF group was considered as two distinctly different groups, one using SDF only $(\mathrm{n}=9)$ and one using SDF prior to GA $(\mathrm{n}=16)$. The SDF only group was younger (mean $=3.2$ versus 3.7 ), had lower $\mathrm{dmft}$ (mean=4 versus 11.1), and had lower frequency of very high dental anxiety ( $0 \%$ versus $15 \%)$ compared to the SDF prior to GA group. In the final tally, among the 90 children treated for ECC voluntarily enrolled in this study, $10 \%$ received only SDF, $36 \%$ received conventional treatment, $37 \%$ received GA only, and $18 \%$ received SDF then GA.

\section{Discussion}

In the clinical practice of dentistry, treatment decisions for early childhood caries (ECC) rely on an assortment of child, parent and clinical factors. ${ }^{24}$ In Japan, silver diamine fluoride (SDF) has been used to treat ECC for more than 40 years. ${ }^{25}$ SDF first became available for use in the United States in 2015. Despite a long and welldocumented history of SDF use in other countries, US clinicians and policymakers have been slow to reach a professional consensus on its utilization and indications. ${ }^{26}$ Specifically, it remains unclear if and when SDF should serve as a long-term alternative to traditional surgical and restorative management of ECC. ${ }^{26,27}$ In the absence of long-term clinical studies and clearer evidencebased guidelines, utilization of SDF remains largely at the discretion of the clinician.

Many published studies have focused on parental acceptance of SDF, ${ }^{28-30}$ but to our knowledge, few studies have reported on the actual use of SDF in clinical practice. 
Table 3 Results of an Ordered Logistic Regression Modeling the Treatment Decision Against the Age, dmft, Insurance Status, and Presence of Very High Dental Anxiety in the Child. The Outcome Was Ordered on Increasing Level of Invasiveness (I=SDF, $2=$ Conventional, $3=\mathrm{GA}$ )

\begin{tabular}{|l|c|c|c|c|c|}
\hline Outcome: Treatment Group & OR & S.E. & Z Score & P value & 95\% CI \\
\hline Child age & 1.07 & 0.21 & 0.37 & 0.7 & 0.74 to 1.57 \\
\hline dmft & 1.11 & 0.06 & 1.92 & 0.06 & 1.00 to 1.23 \\
\hline Child very high dental anxiety & 5.01 & 3.07 & 2.63 & 0.009 & 1.51 to 16.63 \\
\hline $\begin{array}{l}\text { Dental Insurance status (Reference: none) } \\
\quad \text { Medicaid }\end{array}$ & 1.14 & 0.72 & 0.22 & 0.8 & 0.33 to 3.96 \\
$\quad$ Private & 0.83 & 0.58 & -0.27 & 0.8 & 0.21 to 3.28 \\
\hline
\end{tabular}

Abbreviations: SDF, silver diamine fluoride; GA, general anesthesia; OR, odds ratio; S.E., standard error; Cl, confidence interval; dmft, decayed, missing, filled tooth index.

In this pediatric dentistry practice, SDF was presented to parents as a treatment option in every situation where a child's needs were unable to be managed in a timely manner. Nearly-one third of the children studied were treated with SDF. Yet, SDF served as a long-term treatment for only a few children. In these long-term cases, children were younger and had less extensive dental needs than children treated conventionally or under GA. In this study, the majority of children treated with SDF ultimately received dental treatment under GA, a finding consistent with other literature. ${ }^{27}$

Among children planned for extensive restorative treatment under GA, only one-third received prior treatment with SDF. Cost often is suggested as a benefit of SDF and may ultimately factor into a parent's decision to pursue SDF treatment for their child. However, the present analysis found that neither family income nor insurance status was associated with receiving SDF treatment. Treating ECC under a nonsurgical chronic disease management framework is more cost-effective than a conventional or historical framework. ${ }^{31}$ Under chronic disease management, treating ECC should address the etiology as early as possible and not be delayed until symptoms develop. Minimally invasive treatment alternatives such as Hall technique, resin infiltration, interim therapeutic restoration and atraumatic restorative treatment continue to gain traction in pediatric dentistry and public health circles as costeffective alternatives to conventional, surgical caries management. ${ }^{15}$ Finding ways to include SDF among these strategies is imperative to realize its full public health potential.

Previously published survey-based studies suggest variable preference and acceptability of SDF treatment based on tooth location. ${ }^{18,28,29}$ Generally speaking, approximately $60 \%$ of parents accept the black stain on posterior teeth. However, clear parental preference for SDF exists when the only alternative is GA. ${ }^{29}$ The results of this study support a discordance of SDF acceptability in survey studies and in clinical practice, highlighting the difference between actual care decisions and survey responses, as well as potential in surveys for social desirability bias. ${ }^{32}$

Parents of lower socioeconomic status are more likely to find SDF as acceptable treatment. ${ }^{29}$ However, our results paint a slightly different picture. In our study, a child's dental anxiety was the only significant contributor to the treatment decision in a multivariable analysis. In this analysis, having public insurance did not significantly influence clinical decision-making.

The study has limitations. The study recruited a sample of parents and children from a single pediatric dentistry private practice. While this practice serves a diverse demographic cross-section of families, our findings may not be generalizable to a larger population. This study was voluntary, and there could be differences in treatment decisions between participants and non-participants. Multiple clinicians were included in this study. While clinicians in this practice are generally guided by the same practice philosophy, individual differences in how each option was presented in conversations with the parents likely skewed the results. Additionally, we oversampled a high-risk population of children who likely sought treatment at this practice following a referral by a clinician outside the practice. This could explain why only one-third of the control group, and two-thirds of children receiving treatment reported history of a previous dental visit. It is also important to note that in the practice utilized for this study, GA is readily available 
and operating room wait times are relatively short, which could partially explain the lower recommendation, utilization and acceptance of SDF.

Contemporary public health discussions about SDF have largely focused on its potential for major healthcare savings from deferred or avoided visits for GA. ${ }^{33-35}$ The economic assumption is that SDF is being used, in practice, as a longterm caries treatment. The results of the present study should serve to temper expectations surrounding SDF. Our results suggest that for many children, especially those with extensive dental needs, SDF provides minimal long-term benefit in terms of cost-savings since this subgroup ultimately went on to receive treatment under GA. The economic benefit may be greatest for very young children (i.e., 3 years old and younger) with limited extent of disease (i.e., $\mathrm{dmft}=4$ ). Our results suggest that while SDF is unlikely to save the child with approximately 11 cavities from needing restorations or GA, it may save the child with 4 or 5 cavities from having to be sedated or put to sleep. Additionally, in situations where children face long wait times for treatment under GA, SDF may serve as a valuable interim treatment option to halt disease progression. ${ }^{36}$

\section{Conclusion}

For the true economic benefits of SDF to be realized, clearer clinical guidelines are needed to help clinicians and families distinguish when SDF should be used on an interim or long-term basis. The present study identified 2 subgroups of children who received SDF, which may help clarify differences for interim and long-term use of SDF. Future economic analyses should consider different subgroups of children in model assumptions. SDF might offer a greater economic benefit to children with few caries lesions.

\section{Human Subjects Statement}

The University of North Carolina at Chapel Hill Institutional Review Board approved the study under expedited review (existing data) under 45 CFR 46.110 (\#18-0785).

\section{Acknowledgments}

The authors would like to acknowledge Dr. David Moore, Caitlin Baker, and Rachael Purvis for their help with data collection, and Dr. Andy $\mathrm{Ni}$ for his biostatistical consultation.

\section{Disclosure}

Kayla Kopczynski and Beau D. Meyer declare that they have no conflicts of interest in this work.

\section{References}

1. Benjamin RM. Oral health: the silent epidemic. Public Health Rep. 2010;125(2):158-159. doi:10.1177/003335491012500202

2. Fernandes IB, Pereira TS, Souza DS, et al. Severity of dental caries and quality of life for toddlers and their families. Pediatr Dent. 2017;39(2):118-123.

3. Martins-Junior PA. Dental treatment under general anaesthetic and children's oral health-related quality of life. Evid Based Dent. 2017;18(3):68-69. doi:10.1038/sj.ebd.6401249

4. Bruen BK, Steinmetz E, Bysshe T, et al. Potentially preventable dental care in operating rooms for children enrolled in Medicaid. $J$ Am Dent Assoc. 2016;147(9):702-708. doi:10.1016/j.adaj.2016. 03.019

5. Allareddy V, Nalliah RP, Haque M, et al. Hospital-based emergency department visits with dental conditions among children in the United States: nationwide epidemiological data. Pediatr Dent. 2014;36 (5):393-399.

6. Jackson SL, Vann WF, Kotch JB, et al. Impact of poor oral health on children's school attendance and performance. Am J Public Health. 2011;101(10):1900-1906. doi:10.2105/AJPH.2010.200915

7. Frank M, Keels MA, Quiñonez R, et al. Dental caries risk varies among subgroups of children with special health care needs. Pediatr Dent. 2019;41(5):378-384.

8. Divaris K. Precision dentistry in early childhood: the central role of genomics. Dent Clin North Am. 2017;61(3):619-625. doi:10.1016/j. cden.2017.02.008

9. Klingberg G. Dental anxiety and behaviour management problems in paediatric dentistry - a review of background factors and diagnostics. Eur Arch Paediatr Dent. 2008;9(S1):11-15. doi:10.1007/BF03 262650

10. Berkowitz RJ, Amante A, Kopycka-Kedzierawski DT, et al. Dental caries recurrence following clinical treatment for severe early childhood caries. Pediatr Dent. 2011;33(7):510-514.

11. Lee JH, Kim EK, Song IK, et al. Critical incidents, including cardiac arrest, associated with pediatric anesthesia at a tertiary teaching children's hospital. Paediatr Anaesth. 2016;26(4):409-417. doi:10.11 11/pan. 12862

12. Meyer BD, Lee JY, Casey MW. Dental treatment and expenditures under general anesthesia among Medicaid-enrolled children in North Carolina. Pediatr Dent. 2017;39(7):439-444.

13. United States Food and Drug Administration. FDA drug safety communication: FDA review results in new warnings about using general anesthetics and sedation drugs in young children and pregnant women. Available from: https://www.fda.gov/Drugs/DrugSafety/ ucm532356.htm. Accessed December 22, 2020.

14. Meyer BD, Lee JY, Thikkurissy S, et al. An algorithm-based approach for behavior and disease management in children. Pediatr Dent. 2018;40(2):89-92.

15. Slayton RL, Urquhart O, Araujo MWB, et al. Evidence-based clinical practice guideline on nonrestorative treatments for carious lesions: a report from the American Dental Association. $J$ Am Dent Assoc. 2018;149(10):837-849. doi:10.1016/j.adaj.2018.07.002

16. Edelstein BL, Ng MW. Chronic disease management strategies of early childhood caries: support from the medical and dental literature. Pediatr Dent. 2015;37(3):281-287.

17. Fung MHT, Duangthip D, Wong MCM, et al. Randomized clinical trial of $12 \%$ and $38 \%$ silver diamine fluoride treatment. $J$ Dent Res. 2018;97(2):171-178. doi:10.1177/0022034517728496 
18. Clemens J, Gold J, Chaffin J. Effect and acceptance of silver diamine fluoride treatment on dental caries in primary teeth. J Public Health Dent. 2018;78(1):63-68. doi:10.1111/jphd.12241

19. Humphris GM, Morrison T, Lindsay SJ. The modified dental anxiety scale: validation and United Kingdom norms. Community Dent Health. 1995;12(3):143-150.

20. American Academy of Pediatric Dentistry. Guideline on behavior guidance for the pediatric dental patient. Pediatr Dent. 2016;38 (6):185-198

21. Humphris GM, Dyer TA, Robinson PG. The modified dental anxiety scale: UK general public population norms in 2008 with further psychometrics and effects of age. BMC Oral Health. 2009;9:20. doi:10.1186/1472-6831-9-20

22. Harrell FE. Regression Modeling Strategies: With Applications to Linear Models, Logistic and Ordinal Regression, and Survival Analysis. Springer; 2015:72-73.

23. Buldur B. Pathways between parental and individual determinants of dental caries and dental visit behaviours among children: validation of a new conceptual model. Community Dent Oral Epidemiol. 2020;48:280-287. doi:10.1111/cdoe. 12530

24. American Academy of Pediatric Dentistry. Caries-risk assessment and management for infants, children, and adolescents. Ref Manual Pediatr Dent. 2020;243-247.

25. Yamaga R, Yokomizo I. Arrestment of caries of deciduous teeth with diamine silver fluoride. Dent Outlook. 1969;33:1007-1013.

26. Crystal YO, Neiderman R. Evidence-based dentistry update on silver diamine fluoride. Dent Clin North Am. 2019;63(1):45-68. doi:10.1016/j.cden.2018.08.011

27. Davis MR, Johnson EL, Meyer BD. Comparing dental treatment between children receiving and not receiving silver diamine fluoride. J Clin Pediatr Dent. 2020;44(6):400-406. doi:10.17796/ $1053-4625-44.6 .2$
28. Bagher SM, Sabbagh HJ, Aljohani SM, et al. Parental acceptance of the utilization of silver diamine fluoride on their child's primary and permanent teeth. Patient Prefer Adherence. 2019;13:829-835. doi:10.2147/PPA.S205686

29. Crystal YO, Janal MN, Hamilton D, Niederman R. Parental perceptions and acceptance of silver diamine fluoride staining. J Am Dent Assoc. 2017;148(7):510-518. doi:10.1016/j.adaj.2017.03.013

30. Sabbagh H, Othman M, Khogeer L, et al. Parental acceptance of silver diamine fluoride application on primary dentition: a systematic review and meta-analysis. BMC Oral Health. 2020;20:227. doi:10.1186/s12903-020-01195-3

31. Samnaliev M, Wijeratne R, Kwon EG, et al. Cost-effectiveness of a disease management program for early childhood caries. J Public Health Dent. 2015;75(1):24-33. doi:10.1111/jphd.12067

32. Sanzone LA, Lee JY, Divaris K, et al. A cross sectional study examining social desirability bias in caregiver reporting of children's oral health behaviors. BMC Oral Health. 2013;13:24. doi:10.1186/ 1472-6831-13-24

33. Hansen R, Shirtcliff RM, Ludwig S, et al. Changes in silver diamine fluoride use and dental care costs: a longitudinal study. Pediatr Dent. 2019;41(1):35-44.

34. Johhnson B, Serban N, Griffin PM, Tomar SL. Projecting the economic impact of silver diamine fluoride on caries treatment expenditures and outcomes in young U.S. children. J Public Health Dent. 2019;79(3):215-221. doi:10.1111/jphd.12312

35. Hansen RN, Shirtcliff RM, Dysert J, Milgrom PM. Costs and resource use among child patients receiving silver nitrate/fluoride varnish caries arrest. Pediatr Dent. 2017;39(4):304-307.

36. Thomas ML, Magher K, Mugayar L, et al. Silver diamine fluoride helps prevent emergency visits in children with early childhood caries. Pediatr Dent. 2020;42(3):217-220.
Patient Preference and Adherence

\section{Publish your work in this journal}

Patient Preference and Adherence is an international, peer-reviewed, open access journal that focusing on the growing importance of patient preference and adherence throughout the therapeutic continuum. Patient satisfaction, acceptability, quality of life, compliance, persistence and their role in developing new therapeutic modalities and compounds to optimize clinical outcomes for existing disease states are major areas of interest for the journal. This journal has been accepted for indexing on PubMed Central. The manuscript management system is completely online and includes a very quick and fair peer-review system, which is all easy to use. Visit http:// www.dovepress.com/testimonials.php to read real quotes from published authors. 